\title{
GAIA Level 1 Small for Gestational Age
}

National Cancer Institute

\section{Source}

National Cancer Institute. GAIA Level 1 Small for Gestational Age. NCI Thesaurus. Code C128733.

GAIA Level 1 Small for Gestational Age is defined by three criteria: first, weight below the 10th percentile for gestational age; second, assessment of weight by both of the following: a) Newborn weighed within 24 hours of birth; AND b) Weight assessed using a calibrated electronic scale with $10 \mathrm{~g}$ resolution; third, the gestational age is assessed by confirmatory ultrasound during the first trimester, with or without certain LMP, or IUI or embryo transfer date OR by first trimester ultrasound. 